\title{
Acoustic emission instrumentation method for slope monitoring
}

\author{
Bernardo Caicedo ${ }^{1, *}$ and Fernando Patino-Ramirez ${ }^{1}$ \\ ${ }^{1}$ Universidad de Los Andes, Bogotá D. C., Colombia
}

\begin{abstract}
Applications using acoustic emission techniques have shown promising results for slope monitoring. This study proposes a modified active waveguide slope monitoring device with AE measurement at either end of the device which is capable of calculating deformation profiles in real time besides its common use as an alarm method. The coupled calibration methodology allows the location of the slip surface and quantification of slope displacement accounting for the efficiency of the sensors and for attenuation due to distance between an event and the sensors. An analysis software is presented too, in order to propose the algorithms necessary to quantify deformation profiles in real time. The present study proposed some guidelines to perform further field testing based on the procedures and analysis algorithms proposed that showed promising laboratory results.
\end{abstract}

\section{1 introduction}

The occurrence of landslides is a crucial phenomenon affecting the safety and performance of civil structures [1]. Accordingly, slope monitoring is a central topic which concerns both research and professional practice. Current slope monitoring techniques pursue three fundamental characteristics: high temporal resolution, accurate quantification of displacement and cost and time efficiency [2].

Using acoustic emissions (AE) is already an accepted method for identifying and issuing warnings about landslides. Research over the years has shown important advantages of $\mathrm{AE}$ monitoring techniques over widely accepted alternatives [3]. Results have shown advantages regarding the early prediction of slope movements [4], low cost of implementation [5] and a strong correlation between slope displacement and field data [6-9].

Acoustic emission techniques began to be applied to geotechnical engineering in 1970 and include a great diversity of applications from laboratory and field investigations [10-13]. Specific applications for slope monitoring agree on the use of a metallic waveguide which functions as an antenna $[14,15]$ and is coupled to the AE sensor. The device is placed in a borehole filled with clean granular backfill. The accepted monitoring device, known as an active waveguide, has been described in detail by several authors [16-18], and the influence of waveguide materials, geometry and $\mathrm{AE}$ sensors have also been studied $[19,20]$. The use of granular backfill has shown good results, as granular materials exhibit high $\mathrm{AE}$ resulting from strain application [21,22].

Location of the failure plane is fundamental for slope stability analysis and stabilization efforts, but it has not been involved exhaustively as a primary issue in proposals for AE monitoring techniques. Instead, most current research focuses on assessment of the relationship between the AE generation rate and the displacement rate of the device regardless of the location of the failure plane. This study proposes the use of a modified active waveguide which uses two AE sensors, one at the top and one at the bottom of the waveguide, in order to assess the real time location of the failure depth and also permit identification of multiple failure planes as well as the calculation of the deformation profile of the device. Previous authors including [23] have considered the use of two AE sensors with satisfactory results, however, the present study addresses the continuous calculation of failure depths and the influence of AE damping due to the distance to sensors with the proposed calculation algorithm, which was disregarded in the previous study.

Even though the use of $\mathrm{AE}$ sensors at either ends represents an increasing cost as well as water proofing of the device, since only two AE sensors sharing the same data acquisition receiver are needed regardless of the length of the device, the total cost could still be competitive compared to other systems of similar characteristics like SAA inclinometers. In addition, the two sensors can be used to perform two independent calculation routines to achieve method redundancy. The design is shown as a first approach to include a coupled calibration methodology that accounts for attenuation of the $\mathrm{AE}$ reading resulting from changing source-sensor distance and quantifying displacement from $\mathrm{AE}$ retrieved data.

\section{MATERIALS AND METHODS}

\subsection{AE measurement system}

The measurement systems used consists in a windows computer with the software AEwin from Mistras Company, 2 analogue data acquisition cards PCI-2 of 18

\footnotetext{
Corresponding author: bcaicedo@uniandes.edu.co
} 
bits, each one of them is capable to process the data of two AE sensors.

Preamplifiers were used to improve the data acquisition, connecting them between the data acquisition card and the AE sensors; preamplifiers were used configured with a gain of 40dB. Finally, R15D - 80-400 KHZ differential AE sensors were used attached to the waveguide, the preamplifiers and sensors were provided by Physical Acoustic Corporation.

\subsection{AE measurement system}

The device constructed for this study consists of a $10 \mathrm{~mm}$ in diameter polypropylene tube with $0.5 \mathrm{~mm}$ thick walls to confine the granular fill. The waveguide is a $1 \mathrm{~mm}$ in diameter copper filament placed in the centre of the tube. It is welded to two bolsters, one on each head of the device at the points where the $\mathrm{AE}$ sensors are placed. The granular fill consists of a clean homogeneous sand of with uniform particle size. The sand was compacted in $10 \mathrm{~mm}$ thick layers to control density of the granular fill and control homogeneity throughout the instrument. Figure 1 displays the instrument constructed.

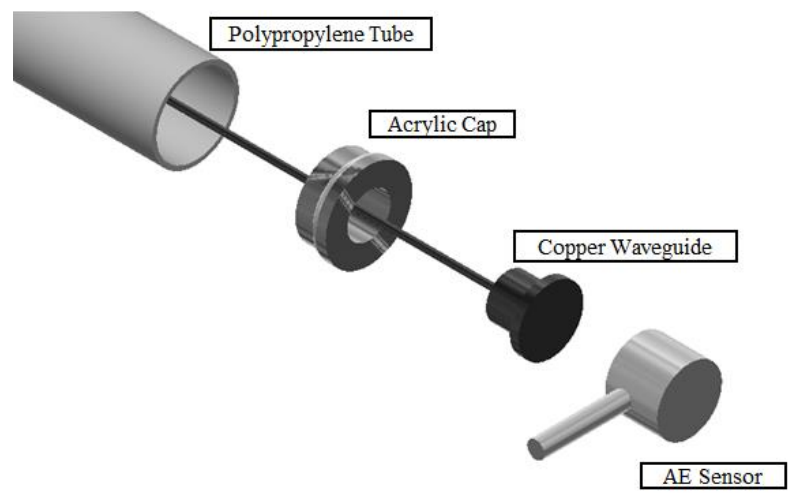

Fig. 1. Instrumentation device (Each end has an AE sensor)

Three different device lengths, 80, 175 and $210 \mathrm{~mm}$, were tested in order to assess the representability of the method and verify the effect of waveguide attenuation. Lengths were measured from both sensor faces. Acoustic emission sensors were attached to the device using commercial cyanoacrylate adhesive.

\subsection{Methodology for event location}

Both sensors coupled to the waveguide record each event. The location of the source event can be found from the arrival times of the hits at each sensor, the length of the device, and the waveguide wave velocity $(3600 \mathrm{~m} / \mathrm{s}$ for copper). Equation 1 permits computation of the event's location.

$$
x_{1}=0.5(L+V \Delta t)
$$

Where $L$ and $V$ are the device length and the waveguide wave velocity respectively, $x_{1}$ and $x_{2}$ are the distances between the event position and each sensor, $t_{1}$ and $t_{2}$ are the elapsed times recorded by the sensors for each event, and $\Delta t=t_{1}-t_{2}$. The analysis algorithm used discards the event location when $\Delta t>t_{\max }$ where $t_{\max }$ is the maximum time elapsed between two hits within the device length as shown on Equation 2.

$$
t_{\max }=L / V
$$

The routine permits location of thousands of events out of which a histogram of computed positions can be created. It follows a distribution curve centred close to the location of the imposed displacement. Dispersion from the correct location is attributed to the contacts between fill particles which lead to additional events that decay rapidly as the distance to induced displacement increases. Figure 2 shows a typical histogram of event locations.

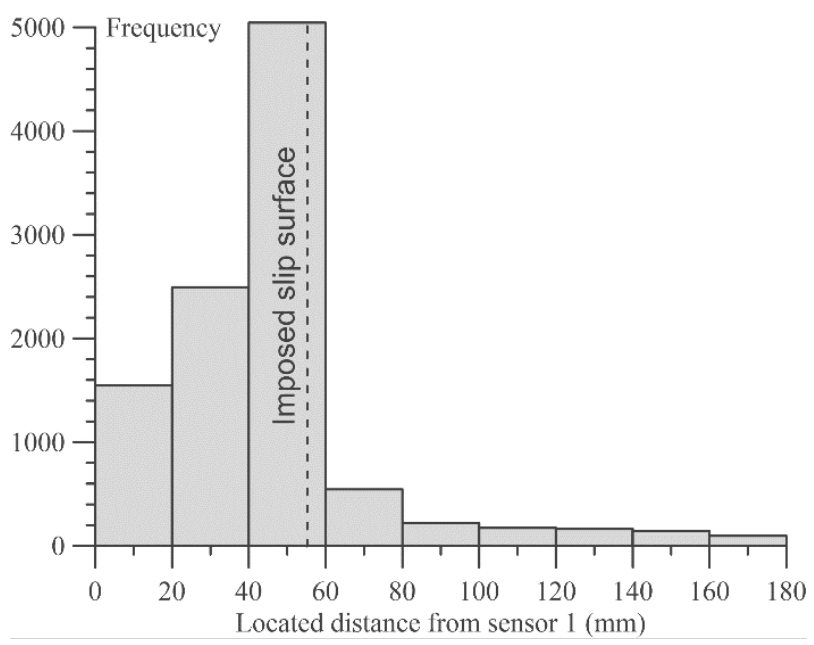

Fig. 2. Typical frequency histogram of events located in a test, at constant velocity $(1 \mathrm{~mm} / \mathrm{min})$ in a $175 \mathrm{~mm}$ long device with induced displacement located at a $\mathrm{Y}$ coordinate of $55 \mathrm{~mm}$.

\subsection{Assessment of the $A E$ attenuation by the monitoring device}

Acoustic signal attenuation is a function of distance from the generated event to sensors and depends on the material used for the waveguide. To assess attenuation, compression was applied at different distances from sensors, as shown in Figure 3. The emission recorded, $\mathrm{AE}_{\mathrm{Rec}}$, was compared with the emission generated, $\mathrm{AE}_{\mathrm{Gen}}$. This procedure took advantage of previous studies and demonstrated that the loading mechanism does not yield significant differences in AE rates [8].

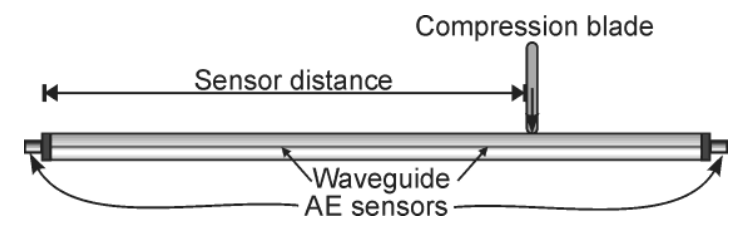

Fig. 3. Experimental setup used for measuring AE signal attenuation.

Results show that attenuation can be successfully adjusted by using an exponential fit as shown in Figure 4, nevertheless, attenuation magnitude depends on the nature of the granular backfill, waveguide material and 
geometry, AE equipment threshold and source event magnitude [18]. Once the slip surface is located the attenuation law permits computation of the emission at the source.

Acoustic previous research on waveguide systems has demonstrated that waveguide systems ae capable of measuring $\mathrm{AE}$ detected from granular shearing at a deep shear surfaces $[7,8]$, the attenuation law provided is particular to the device tested and the $\mathrm{AE}$ equipment described above.

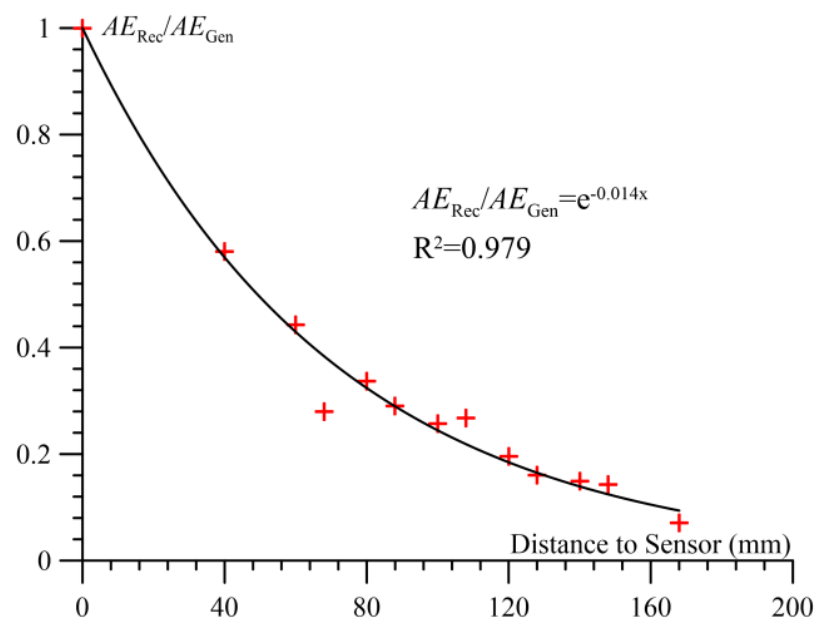

Fig. 4. Attenuation of acoustic emission, as function of distance from source to sensor.

\subsection{Calibration for horizontal displacement and event location}

The experimental setup used to find the relationship between $\mathrm{AE}$ Counts and horizontal displacement consisted of placing the device in a hole drilled into two aligned wooden blocks. The bottom block was fixed to the base while the upper one was only able to move horizontally. The upper block was displaced using an electrical servo-actuator set at speeds between 0.25 and $7 \mathrm{~mm} / \mathrm{min}$ up to a displacement of $50 \%$ of the device diameter. Figure 5 schematically illustrates the experimental setup.

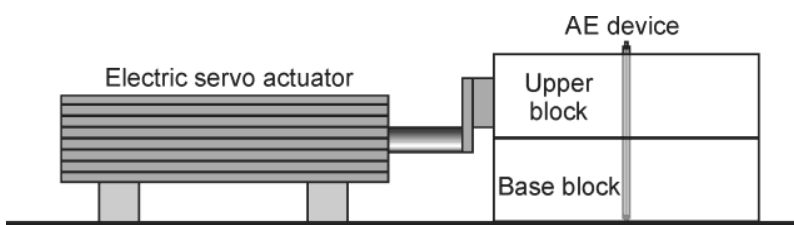

Fig. 5. Experimental setup with induced horizontal displacement of upper block.

These tests showed an initially low AE zone during the 1st millimetre of displacement which is attributable to accommodation to the experimental setup. Afterwards, linear $\mathrm{AE}$ generation was retrieved. Figure 6 shows a typical result of $\mathrm{AE}$ acquisition, as well as the linear fit characterising the $\mathrm{AE}$ count rate after discarding the initial accommodation zone.

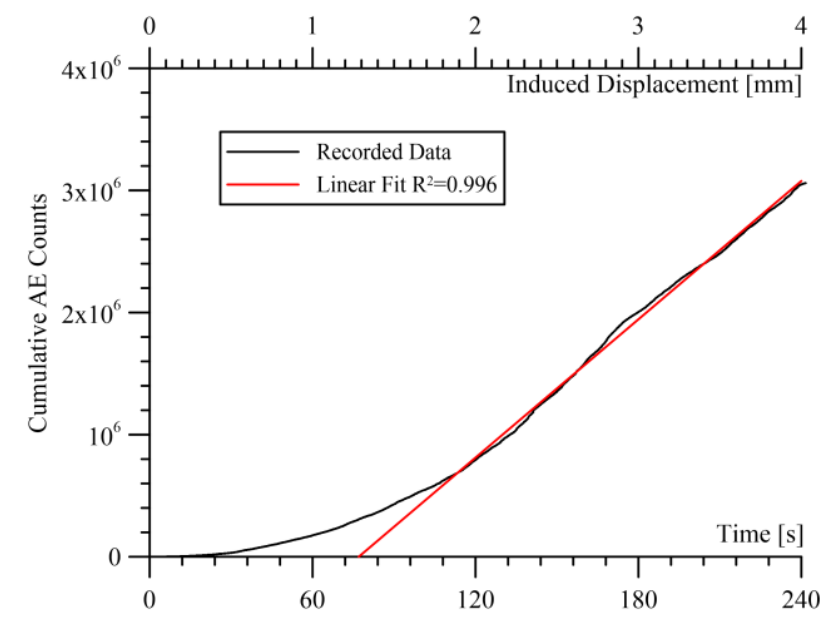

Fig. 6. Typical AE acquisition, induced displacement at constant velocity $(1 \mathrm{~mm} / \mathrm{min})$.

Corrected values of $\mathrm{AE}$ rates for each test were plotted and compared to analyse their behaviour. The relationship between the $\mathrm{AE}$ rate and the displacement rate showed a linear trend $\left(\mathrm{R}^{2}=0.938\right)$ as can be seen in Figure 7. This agrees with previously obtained results [8].

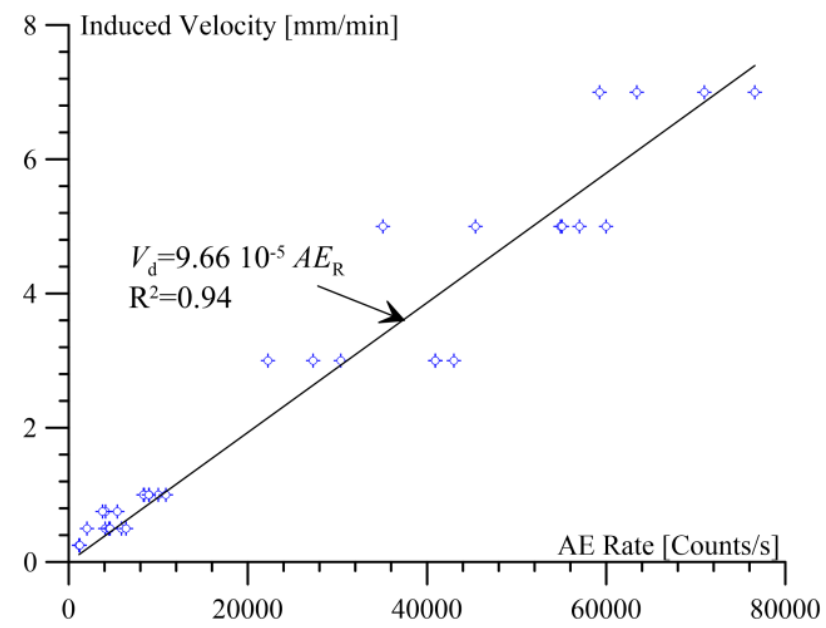

Fig. 7. Relationship between $\mathrm{AE}$ rate and imposed displacement rate (velocity).

\subsection{Integrated algorithm for slip location and displacement quantification}

Once the device was properly calibrated, a Matlab application was created to locate events and quantify displacement rates so that a displacement profile could be created from acquired data. The input parameters of the software are basically the geometry of the device and calibration curves shown above.

The algorithm defined for the software analyses allotted data in time periods of equal duration. Within each time lapse the $\mathrm{AE}$ count rate is assumed to be constant, and its value is calculated from the linear fit of the cumulative count profile within the given time lapse. Afterwards, the MATLAB location routine identifies the coordinates of several $\mathrm{AE}$ events within the actual time period as a frequency histogram, as shown in the methodology for event location. Then, the mean of the $\mathrm{AE}$ 
events is assigned as the location of the displacement for the given time lapse.

The AE count rate is corrected for the attenuation effect using the previously found location of the displacement and the correction curve shown on Figure 4. Finally, the displacement rate of the given time lapse is correlated from the calibration curve between the AE rate and the deformation rate (Figure 7).

\subsection{Comparison between induced and calculated displacement profiles}

The results obtained when the device and the software were evaluated to validate the behaviour of the proposed method showed a good relationship between induced and calculated horizontal displacement as well as for location of the failure plane. Assessment tests addressed variations of the induced deformation rate, device length and location of the failure plane. Figure 8 compares deformation profiles in a group of tests performed at a displacement rate of $0.5 \mathrm{~mm} / \mathrm{s}$ and a total induced displacement of $4.5 \mathrm{~mm}$.

Deviation of calculated results from imposed displacement was about $+/-1 \mathrm{~mm}$. The results showed good agreement between the calculated location of the slip plane and the actual position of the displacement with a deviation of about $+/-5 \mathrm{~mm}$ in all tests performed.

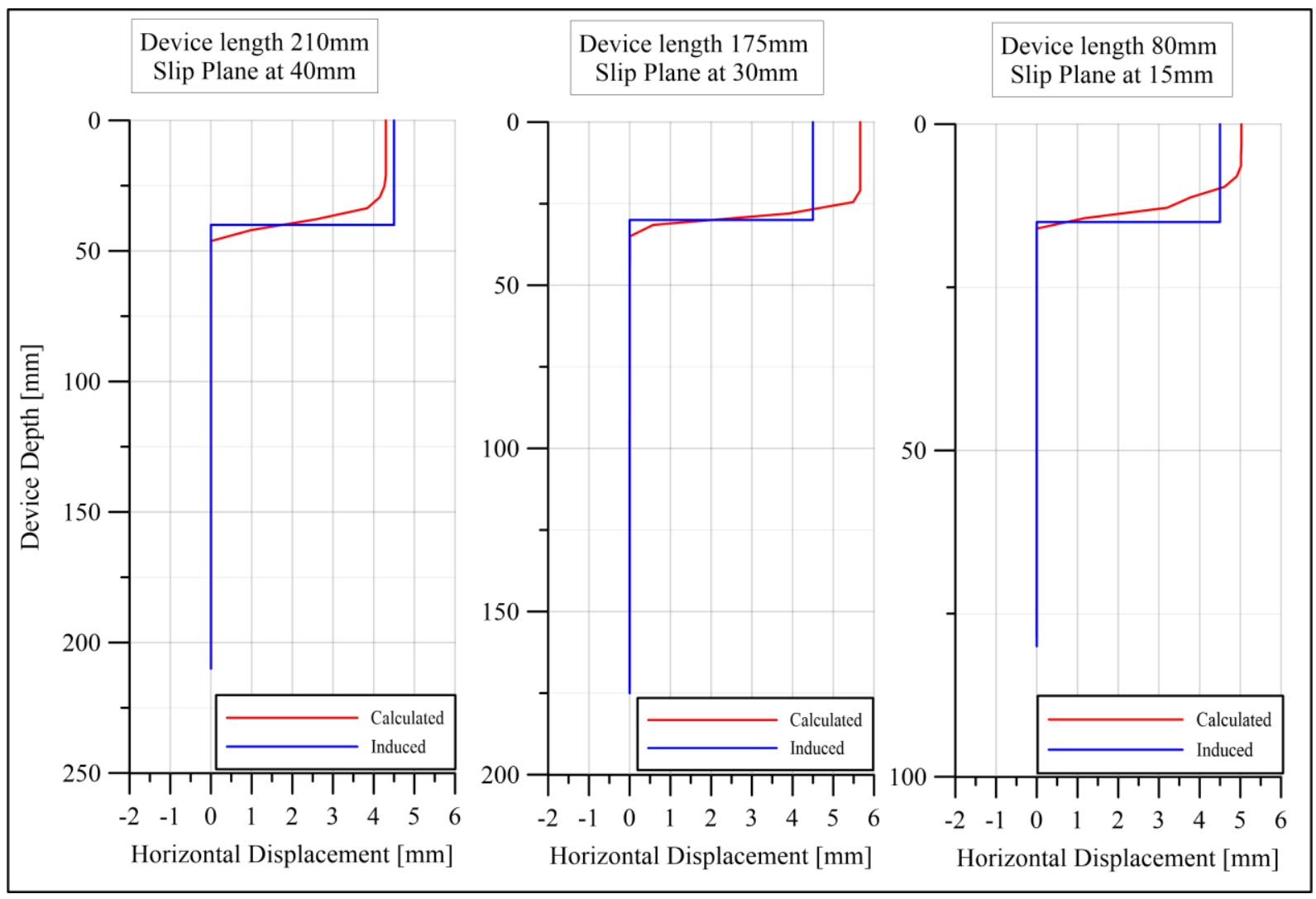

Fig. 8. Comparison between induced and calculated displacements, tests performed at $0.5 \mathrm{~mm} / \mathrm{min}$ to $4.5 \mathrm{~mm}$ of total displacement for various positions of the slip plane and various device lengths.

\section{CONCLUSIONS}

The results obtained from the device and software shows the promising potential of the device proposed, the calibration and software algorithm of the active waveguide instrument method for real time-measurement and for providing warnings of landslides.

The capabilities of the method fulfil the required functions for slope monitoring devices. Moreover, the method could provide several additional advantages including early detection of landslides, cost and time efficiency, real time monitoring and larger measurement thresholds for horizontal displacement which have been shown in previous research regarding the use of active waveguide method.
The obtained results and device precision in laboratory scale show a promising opportunity to perform field testing in order to validate their performance in real slopes, the proposed device and algorithms represent a guideline to test the use of the active waveguide as an actual measuring device besides an alarm method, keeping all the already accepted advantages of the method. 


\section{References}

1. S. Leroueil. Géotech., 51(3), 197-243. (2001)

2. S. Uhlemann, A. Smith, J. Chambers, N. Dixon, T. Dijkstra, E. Haslam. J. Mackay. Geomorp., 253, 438-451 (2016).

3. N. Dixon, R. Moore, M. Spriggs, A. Smith, P. Meldrum, \& R. Siddle. Engineering Geology for Society and Territory - Volume 2: Landslide Processes pp. 117-120 (2015).

4. N. Dixon, M. P. Spriggs, A. Smith, P. Meldrum, \& E. Haslam. Landslides, (Oct. 2013), 549-560. (2014).

5. N. Dixon, M. P. Spriggs, P. Meldrum, \& E. Haslam. From https://dspace.lboro.ac.uk/dspacejspui/handle/2134/10239 (2012).

6. N. Dixon, \& M. Spriggs. Can. Geotech. Jour., 44(8), 966-976 (2007).

7. A. Smith, N. Dixon, P. Meldrum, E. Haslam, \& J. Chambers. Géotech. Letters, 4(4), 255-261 (2014).

8. A. Smith, \& N. Dixon. Can. Geotech. Journal, 52, 413-425 (2015).

9. N. Berg, A. Smith, S. Russell, N. Dixon, D. Proudfoot, and A. Take. Can. Geot.. Jour. 55, no. 10: 1475-1488 (2018).

10. H. R. Hardy, NDT and E Internat. 27(4), 191-200 (1994).

11. R. M. Koerner, W. M. McCabe, \& A. Lord E. J. In Acoustic Emission in Geotechnical Engineering Practice, ASTM STP 750 (pp. 93-141) (1981).

12. W. Mao, S. Aoyama, S. Goto, \& I. Towhata. Journal of Appl. Geoph., 119, 119-127 (2015).

13. A. Zaki, H. K. Chai, H. A. Razak, \& T. Shiotani. Compt. Rend. - Geosc., 346(9-10), 223-232 (2014).

14. D. S. Cheon, Y. B. Jung, E. S. Park, W. K. Song, \& H. I. Jang, Eng. Geol., 121(1-2), 75-88 (2011).

15. H. R. Hardy, NDT \& E International, 27(4), 220 (1994).

16. N. Dixon, R. Hill, \& J. Kavanagh, Proc. of the ICE - Geotech. Eng., 156(2), 83-95 (2003).

17. N. Dixon, A. Smith, M. Spriggs, A. Ridley, P. Meldrum, \& E. Haslam. Proc. of Inst. of Civil Eng. - Geotech. Eng. Journal, 168 (2015).

18. A. Smith. (2015). Quantification of slope deformation behaviour using acoustic emission monitoring. Loughborough University Institutional Repository.

19. J. C. Kapil, P. Datt, A. Kumar, K. Singh, V. Kumar, \& P. K. Satyawali. Cold Reg. Sc and Tech., 101, 1-13 (2014).

20. B. R. A. Wood, T. C. Flynn, R. W. Harris, \& L. M Noyes. Acoust. Austr., 19(3), 3-87 (1991).

21. F. Fernandes, A. I. Syahrial, \& J. R. Valdes, Geotech. Test. Journal, 33(5), 102501 (2010).
22. G. Michlmayr, D. Cohen, \& D. Or. Earth-Sc. Rev., 112(3-4), 97-114 (2012).

23. I. Nakajima, M. Negishi, M. Ujihira, \& T. Tanabe. In R. Hardy (Ed.), Acoustic emission/Microseismic activity in geologic structures and materials. Proc. of the fifth conf. (pp. 505-519). Trans Tech publications. (1991). 